\title{
Storm type effects on super Clausius-Clapeyron scaling of intense rainstorm properties with air temperature
}

\author{
P. Molnar ${ }^{1}$, S. Fatichi ${ }^{1}$, L. Gaál ${ }^{2, *}$, J. Szolgay ${ }^{2}$, and P. Burlando ${ }^{1}$ \\ ${ }^{1}$ Institute of Environmental Engineering, ETH Zurich, Zurich, Switzerland \\ ${ }^{2}$ Slovak University of Technology, Bratislava, Slovakia \\ *now at: Technical University of Vienna, Vienna, Austria
}

Correspondence to: P. Molnar (molnar@ifu.baug.ethz.ch)

Received: 11 July 2014 - Published in Hydrol. Earth Syst. Sci. Discuss.: 29 July 2014

Revised: 19 March 2015 - Accepted: 23 March 2015 - Published: 16 April 2015

\begin{abstract}
Extreme precipitation is thought to increase with warming at rates similar to or greater than the water vapour holding capacity of the air at $\sim 7 \%{ }^{\circ} \mathrm{C}^{-1}$, the so-called Clausius-Clapeyron (CC) rate. We present an empirical study of the variability in the rates of increase in precipitation intensity with air temperature using 30 years of $10 \mathrm{~min}$ and $1 \mathrm{~h}$ data from 59 stations in Switzerland. The analysis is conducted on storm events rather than fixed interval data, and divided into storm type subsets based on the presence of lightning which is expected to indicate convection. The average rates of increase in extremes (95th percentile) of mean event intensity computed from $10 \mathrm{~min}$ data are $6.5 \%{ }^{\circ} \mathrm{C}^{-1}$ (no-lightning events), $8.9 \%{ }^{\circ} \mathrm{C}^{-1}$ (lightning events) and $10.7 \%{ }^{\circ} \mathrm{C}^{-1}$ (all events combined). For peak $10 \mathrm{~min}$ intensities during an event the rates are $6.9 \%{ }^{\circ} \mathrm{C}^{-1}$ (no-lightning events), $9.3 \%{ }^{\circ} \mathrm{C}^{-1}$ (lightning events) and $13.0 \%{ }^{\circ} \mathrm{C}^{-1}$ (all events combined). Mixing of the two storm types exaggerates the relations to air temperature. Doubled CC rates reported by other studies are an exception in our data set, even in convective rain. The large spatial variability in scaling rates across Switzerland suggests that both local (orographic) and regional effects limit moisture supply and availability in Alpine environments, especially in mountain valleys. The estimated number of convective events has increased across Switzerland in the last 30 years, with $30 \%$ of the stations showing statistically significant changes. The changes in intense convective storms with higher temperatures may be relevant for hydrological risk connected with those events in the future.
\end{abstract}

\section{Introduction}

The water vapour holding capacity of the air increases with temperature by about $7 \%{ }^{\circ} \mathrm{C}^{-1}$, the so-called ClausiusClapeyron (CC) rate. Consequently, precipitation is also expected to increase with air temperature. While changes in mean precipitation are constrained by the energy budget at the Earth's surface and are typically smaller than the $\mathrm{CC}$ rate, $\sim 2-3 \%{ }^{\circ} \mathrm{C}^{-1}$ (e.g. Schneider et al., 2010; Roderick et al., 2014; Allan et al., 2014), changes in extreme precipitation from fully saturated air masses have been postulated to occur at the $\mathrm{CC}$ rate, or even higher if local moisture convergence takes place (e.g. Trenberth, 1999; Trenberth et al., 2003; Loriaux et al., 2013).

Simulations of daily extreme precipitation by climate models have shown a range of sensitivities to air temperature globally. Extratropical precipitation was shown to increase at about the thermodynamically constrained $\mathrm{CC}$ rate, while tropical precipitation change varied widely between models because of the dependence of tropical rainfall on moist convective processes in the atmosphere, especially vertical velocity (e.g. Pall et al., 2007; O'Gorman and Schneider, 2009a, b; O'Gorman, 2012). Satellite observations indicate that the rate of increase in extreme daily rainfall with a warming climate in the tropics may be greater than that simulated by some models (Allan and Soden, 2008), while ground observations have also shown a decrease in extreme rainfall in some parts of the tropics (Utsumi et al., 2011). Overall, local responses are strongly dependent on changes in large-scale 
circulation patterns and the physical nature and seasonality of rainfall regimes (e.g. Berg et al., 2009; Allan et al., 2014).

Analyses of precipitation data at sub-daily resolutions generally show higher rates of increase in intensity with temperature. Data demonstrations started with the De Bilt data set, where Lenderink and Van Meijgaard (2008) found that a $\mathrm{CC}$ rate of increase in extreme hourly intensities accelerated to a doubled $\mathrm{CC}$ rate of approximately $14 \%{ }^{\circ} \mathrm{C}^{-1}$ for temperatures above $12{ }^{\circ} \mathrm{C}$. This $2 \mathrm{CC}$ rate was attributed to a positive feedback between water vapour and the dynamics of precipitation formation in convective clouds (Lenderink and Van Meijgaard, 2010; Loriaux et al., 2013). The 2CC rates were subsequently found in other studies using hourly and higher resolution data. It was also argued that at very high temperatures the relation between precipitation intensity and temperature may become negative due to atmospheric moisture supply limitations (e.g. Hardwick Jones et al., 2010; Lenderink and Van Meijgaard, 2010; Lenderink et al., 2011; Westra et al., 2014; Panthou et al., 2014).

Available observational evidence to date suggests that precipitation-temperature scaling rates may vary widely in space and are time resolution dependent (e.g. Haerter et al., 2010; Hardwick Jones et al., 2010; Shaw et al., 2011; Mishra et al., 2012; Westra et al., 2014; Panthou et al., 2014). An alternative (statistical) explanation for super-CC rates has been put forward, that mixing storm types - stratiform low intensity rainfall at low temperatures and convective high intensity rainfall at high temperatures - may lead to the appearance of super-CC rates (Haerter and Berg, 2009; Berg and Haerter, 2013a). Berg et al. (2013b) demonstrated on a large data set in Germany that super-CC scaling is in fact dominated by convective rain, which is more sensitive to increases in air temperature. Quantifying the effect of storm type mixing remains an important and open problem (e.g. Lenderink and Van Meijgaard, 2010; Loriaux et al., 2013; Westra et al., 2014).

In this article we add empirical evidence to the picture of variability in scaling slopes between intense rainstorm properties and air temperature from observations at $10 \mathrm{~min}$ and $1 \mathrm{~h}$ resolutions at 59 stations with 30 years of record in Switzerland. We focus only on rainfall events, aiming to address three key questions which complement previous studies:

a. Is the rate of increase in rainfall extremes with temperature affected by storm type (stratiform or convective) and what is the effect of combining storm types on the estimated scaling slopes across many stations? For the storm type separation we used a classification of events with lightning data (Gaál et al., 2014) and a convectivity index (Llasat, 2001). We also looked at evidence of possible changes in the stratiform-convective event split in the past 30 years.

b. Are super-CC rates evident when integral storm event properties (e.g. total depth, mean and peak intensity, and duration) are related to air temperature, as opposed to using fixed time intervals (e.g. daily or hourly) like in most previous studies? It has been cautioned that a fixed (coarse) time interval may not provide an accurate picture of rainfall variability (Haerter et al., 2010). Most notably, the temporal resolution has a strong impact on event duration, which especially for short heavy rainstorms can only be resolved accurately by $10 \mathrm{~min}$ and higher resolution data.

c. Are there coherent spatial patterns in the rates of increase in event intensity with air temperature across Switzerland? With many local orographic effects on precipitation formation as well as different large-scale atmospheric moisture flux patterns (e.g. south-north of the main Alpine divide), Switzerland offers the possibility to investigate the spatial variability in the relations of extreme rainfall to air temperature (e.g. Ban et al., 2014). To address this question we divided the stations into four distinct geo-climatic regions and looked for differences between them.

\section{Data and methods}

\subsection{Meteorological data}

We used $10 \mathrm{~min}$ and $1 \mathrm{~h}$ precipitation, air temperature, and relative humidity measurements at 59 stations of the SwissMetNet network (MeteoSwiss) for the period 1981-2011 (31 years) and $10 \mathrm{~min}$ lightning strike data for the period 1987-2011 (25 years). The stations were selected based on adequate record length without missing data, excluding stations at highest altitudes where precipitation measurement is less reliable. The stations ranged from $203 \mathrm{~m}$ a.s.l. (Magadino) to $2287 \mathrm{~m}$ a.s.l. (Guetsch) in altitude. The stations were divided into four geo-climatic regions: Plateau in northern Switzerland $(n=25)$, pre-Alps north of the main Alpine divide $(n=10)$, high Alps $(n=14)$, and Tessin in southern Switzerland ( $n=10)$ (Fig. 1).

Precipitation at SwissMetNet stations is recorded by a heated tipping-bucket rain gauge (Lambrecht) with orifice area $200 \mathrm{~cm}^{2}$ and tip resolution $0.1 \mathrm{~mm}$. The data are quality checked and have been used in previous studies by the authors (Molnar and Burlando, 2008; Paschalis et al., 2012, 2013, 2014). Intensity correction is applied, but correction for wind is not. The wind-driven undercatch is lower for higher intensity rain (Chvila et al., 2005), and we assume that it does not affect the correlations of extremes with air temperature appreciably. Air temperature is a standard measurement by a ventilated thermometer at $2 \mathrm{~m}$ height. Relative humidity is measured by a dew-point mirror (Thygan). Lightning strike count is derived from the induced electric charge by ground antennas at the stations. Separation between cloud-to-ground and intra-cloud lightning is not possible. We use close and distant $(<30 \mathrm{~km})$ strikes as an indication of convective potential of the atmosphere in the vicinity of the station. More 


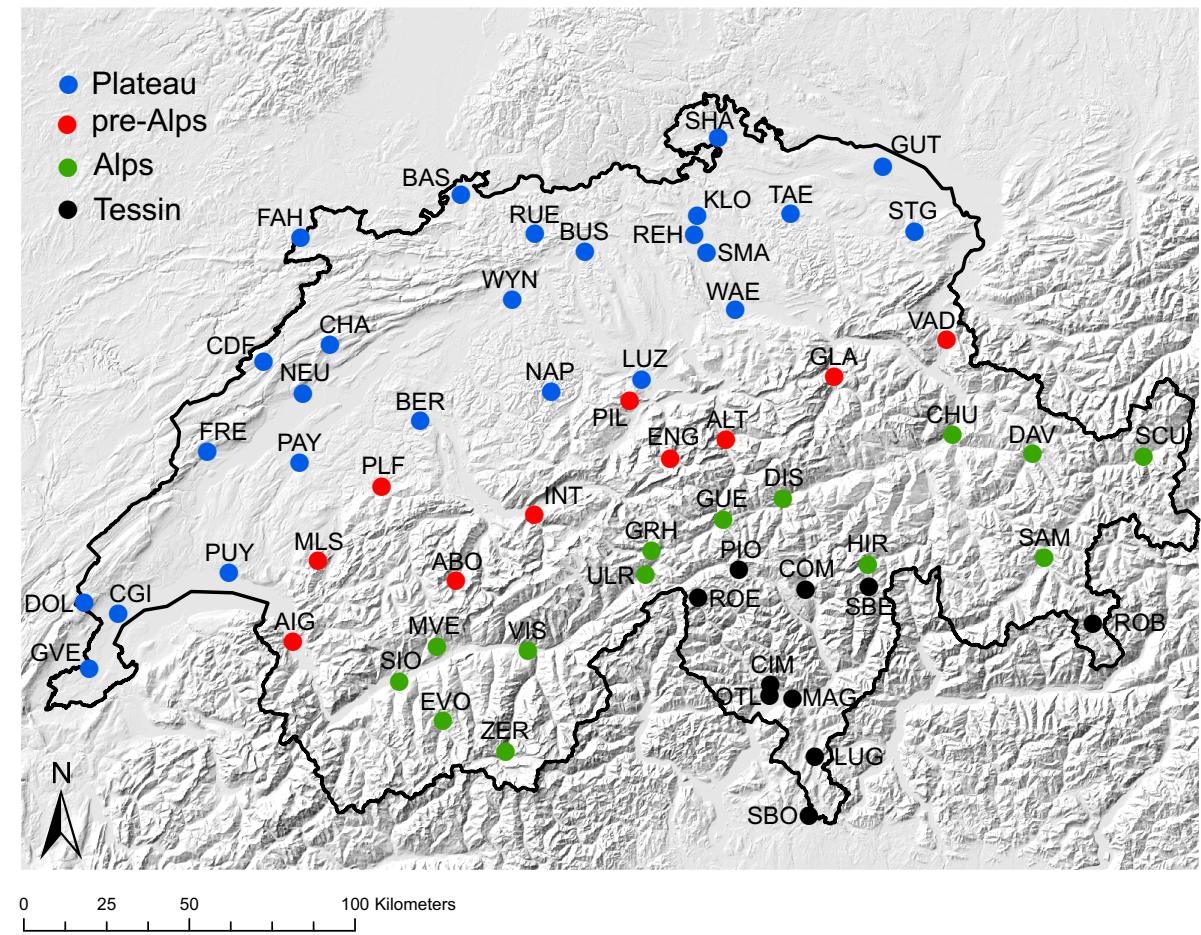

Figure 1. Map of the 59 analysed stations in Switzerland divided into four regions: Plateau, pre-Alps, Alps and Tessin. The labels list station codes. The Tessin region represents all stations that are in valleys facing south of the main Alpine divide.

information about the lightning strike data can be found in Gaál et al. (2014).

\subsection{Selection of rainfall events}

Our main unit of analysis in this study is the rainfall event. We defined independent events as wet periods separated by a continuously dry interval with duration greater than $t_{i}$. For each event we determined four main properties: total rainfall depth $R$, event duration $d$, mean rainfall intensity $I_{\mathrm{m}}=R / d$, and peak (maximum) intensity during the event $I_{\mathrm{p}}$ at a given temporal resolution. In the identification of events we ignored single tips, i.e. intervals with $0.1 \mathrm{~mm}$ of measured rainfall.

To each event we assigned a mean daily air temperature and relative humidity on the day of the event, or over several days if the event was spread over more than 1 day. Because we are interested in intense rainfall events only and want to avoid snow and mixed rain-snow events, we limit the analysis to events in the warm season (April-September) and with temperature during the events exceeding $4{ }^{\circ} \mathrm{C}$. The time interval used to separate events was chosen as $t_{i}=2 \mathrm{~h}$ following the work of Gaál et al. (2014). This separation time is a balance between statistical considerations of independence between events (e.g. Grace and Eagleson, 1967; RestrepoPosada and Eagleson, 1982) and the need to limit intra-event gaps and ensure that peak event intensities are indeed related to the actual storm (e.g. Dunkerley, 2010).
The temporal resolution has a strong effect on event $d$ and $I_{\mathrm{p}}$. Event duration is better resolved with $10 \mathrm{~min}$ than with $1 \mathrm{~h}$ data, and this effect is particularly important for shortduration convective summer events, which are often shorter than $1 \mathrm{~h}$. Peak intensity during the event is also greater at $10 \mathrm{~min}$ than $1 \mathrm{~h}$ resolution because of intra-event intensity fluctuations. In the article we focus mostly on the results with 10 min data, but we also present some results with $1 \mathrm{~h}$ data to quantify the effect of temporal resolution.

\subsection{Convective-stratiform rain}

We divide all events in the period 1987-2011 into two exclusive subsets: those accompanied by lightning and those that are not. Overall, between 25 and $50 \%$ of the warm season events are accompanied by lightning, depending on station location. Insofar as heavy convective summer thunderstorms are associated with lightning, we consider the presence of lightning to be a good first-order discriminator between convective and stratiform rain. In the $10 \mathrm{~min}$ data we associated events with the convective set also if they were preceded by lightning strikes within $30 \mathrm{~min}$ of the beginning of rainfall.

The convective-stratiform rain separation by lightning is based on observed associations between intra-cloud and cloud-to-ground lightning and the type and amount of rain (e.g. Tapia et al., 1998; Petersen and Rutledge, 1998; Price and Federmesser, 2006; Grungle and Krider, 2006; Yair et al., 2010). Other methods exist for the identification of 
convective rain from ground synoptic observations of clouds, state of weather and/or rain intensity fluctuations, radar observations, and event duration (e.g. Pešice et al., 2003; Lang et al., 2003; Rigo and Llasat, 2004; Llasat et al., 2005, 2007; Berg et al., 2013b; Rulfová and Kyselý, 2013; Panthou et al., 2014). We also recognise that embedded convection may also occur in cold fronts outside of the warm season. Despite these limitations, we nevertheless think that the occurrence of lightning is a reasonable discriminator for the presence of convection in the warm season in Switzerland.

For the entire 1981-2011 record we used an additional method to classify events by their convective nature using the convectivity index $\beta$ of Llasat (2001), which is defined as the ratio of the rainfall depth that fell with intensities $i>I^{*}$ to the total event depth $R$. We classified events as non-convective if $\beta<0.2$, moderately convective if $0.2<$ $\beta<0.8$ and strongly convective if $\beta>0.8$ (Llasat, 2001). The threshold intensity $I^{*}$ is a parameter which needs to be estimated for every station. We adopt the method of Gaál et al. (2014) which uses the presence of lightning to classify convective events as those where $I_{\mathrm{p}}>I^{*}$. The threshold $I^{*}$ is found with an acceptable error $\alpha$ of non-lightning events classified as convective (false positives, type I error) from the period with available lightning data. By choosing the same $\alpha$ for all stations we have an objective way to compare the properties of the events and their relation to temperature between stations. To analyse possible changes in the frequency of convective events we applied a non-parametric Mann-Kendall trend test (e.g. Fatichi et al., 2009) to the number of events per year during which $I_{\mathrm{p}}$ exceeded $I^{*}$ over the period 19812011 using $10 \mathrm{~min}$ data. For more details on the calibration of $I^{*}$, see Gaál et al. (2014).

\subsection{Correlation with air temperature}

Most previous studies have investigated precipitation intensities at fixed time intervals (e.g. $10 \mathrm{~min}$, hourly, daily) by binning the data into temperature ranges, the so-called temperature binning (TB) method. In each temperature bin a precipitation intensity quantile is found and the intensitytemperature data pairs are used to search for $\mathrm{CC}$ or super-CC scaling rates for different temperature ranges (e.g. see the review in Westra et al., 2014).

In our article we chose not to search for a perceived change in the slope of the intensity-temperature relation at a certain threshold temperature, but rather we find a scaling slope for the entire range of temperatures above $4^{\circ} \mathrm{C}$ at each station. We do this because we want to avoid the effect of snowfall at low temperatures, and we have a large difference in temperature ranges between stations covering altitudes from 200 to about $2300 \mathrm{~m}$ a.s.l. We also estimated the scaling slope by the quantile regression $(\mathrm{QR})$ method applied to logarithmically transformed intensity data. This method does not require binning and is unbiased with respect to sample size (Wasko and Sharma, 2014). The results of the QR and the TB method computed with exponential regression of intensitytemperature data pairs were compared and relevant results of the TB method are presented in the Supplement.

Since we do not use fixed time intervals, we estimate the scaling slopes for quantiles of event properties $\left(R, d, I_{\mathrm{m}}, I_{\mathrm{p}}\right)$ and mean air temperature on the day of the event. Event variables have been used in some recent studies (Haerter et al., 2010; Berg et al., 2013b; Mosley et al., 2013; Panthou et al., 2014) and have the advantage of being statistically independent outcomes of the precipitation process at the event scale. We focus in particular on mean and peak event intensity and on the 95th percentile, although we report results for other percentiles as well (50th, 90th and 99th). $I_{\mathrm{m}}$ reflects the mean atmospheric conditions leading to precipitation, while $I_{\mathrm{p}}$ represents short (10 min or $1 \mathrm{~h}$ ) periods of highest rain intensity during an event.

\section{Results and discussion}

\subsection{Analysis of all events}

Histograms of the estimated scaling slopes fitted to event $d$, $R, I_{\mathrm{m}}$ and $I_{\mathrm{p}}$ with mean daily air temperature for the 95th percentile of all storms regardless of storm type, i.e. the $5 \%$ largest values in the sample of all events (quantile regression method), are shown in Fig. 2 for $10 \mathrm{~min}$ and $1 \mathrm{~h}$ data. There is a clear and consistent negative relation between event duration $d$ and air temperature visible in both $10 \mathrm{~min}$ and $1 \mathrm{~h}$ data, indicating that shorter storms consistently take place during warmer days. The total event depth $R$ is poorly related to air temperature, with large variability among stations (see also Haerter et al., 2010).

As expected, the strongest relations to air temperature come from mean and peak event intensity. The average scaling slopes from all stations substantially exceed the $\mathrm{CC}$ rate. For mean event intensity these are $10.7 \%{ }^{\circ} \mathrm{C}^{-1}$ for $10 \mathrm{~min}$ data and $9.5 \%{ }^{\circ} \mathrm{C}^{-1}$ for $1 \mathrm{~h}$ data (Table 1). For peak event intensity the scaling slopes are $13.0 \%{ }^{\circ} \mathrm{C}^{-1}$ for $10 \mathrm{~min}$ data and $8.9 \%{ }^{\circ} \mathrm{C}^{-1}$ for $1 \mathrm{~h}$ data (Table 2). Although peak event intensity increases with temperature at a significantly higher rate than mean event intensity using 10 min data, this effect is not visible or is even reversed in the hourly data. This indicates the limitations of the coarse hourly resolution in capturing peak intensity fluctuations during a rainstorm.

\subsection{Effect of storm type mixing}

One of the key questions here is how storm type contributes to the rainfall intensity-temperature relation. An example of the estimated scaling slopes by the quantile regression and temperature binning methods is shown for the Wynau station (WYN, Plateau region) for all events and subsets with and without lightning (Fig. 3). The scaling slopes for no-lightning and lightning sets are practically identical at $6 \%{ }^{\circ} \mathrm{C}^{-1}$, while when both sets are analysed together we 

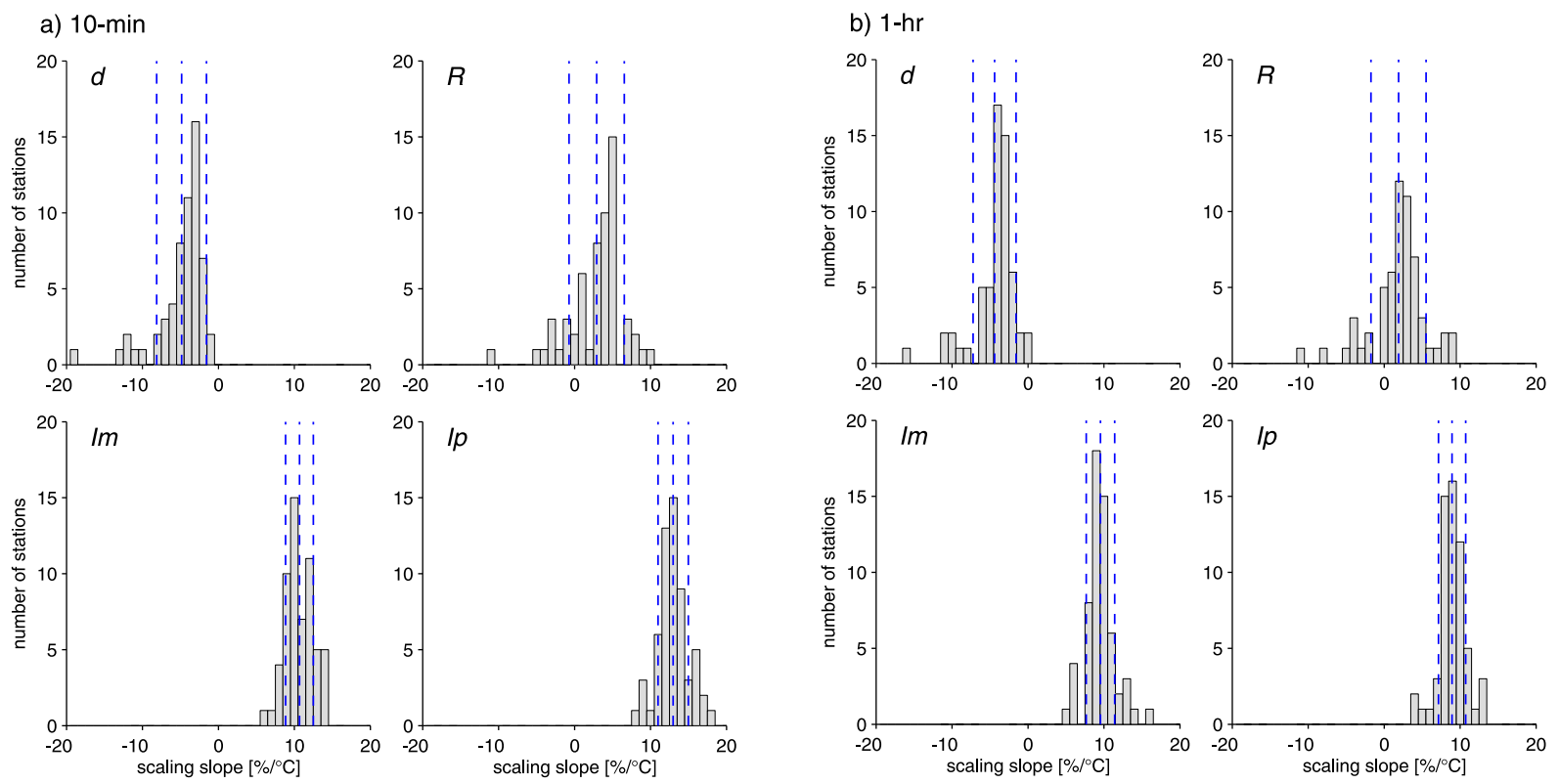

Figure 2. Histograms of the scaling slopes in $\%{ }^{\circ} \mathrm{C}^{-1}$ fitted to the 95 th percentiles of event duration $d$, total storm depth $R$, mean intensity $I_{\mathrm{m}}$ and peak intensity $I_{\mathrm{p}}$ for 59 stations computed with the quantile regression method. Data are shown for (a) $10 \mathrm{~min}$ and (b) $1 \mathrm{~h}$ resolutions. Vertical dashed lines indicate the mean \pm 1 standard deviation. The same figure for the temperature binning method is in the Supplement.

Table 1. Means of the regression slopes in $\%{ }^{\circ} \mathrm{C}^{-1}$ fitted to the 95 th percentiles by quantile regression \pm 1 standard deviation. Slopes are reported for mean $I_{\mathrm{m}}$ event intensity for $10 \mathrm{~min}$ and $1 \mathrm{~h}$ time resolutions for all events, no-lightning events, lightning events, and storms grouped by the convectivity index $\beta$.

\begin{tabular}{lcccccc}
\hline$I_{\mathrm{m}}(10 \mathrm{~min})$ & All events & No lightning & Lightning & $\beta<0.2$ & $0.2<\beta<0.8$ & $\beta>0.8$ \\
\hline All stations $(n=59)$ & $10.7 \pm 1.9$ & $6.5 \pm 2.5$ & $8.9 \pm 2.5$ & $3.1 \pm 0.9$ & $3.2 \pm 1.5$ & $4.9 \pm 4.1$ \\
Plateau $(n=25)$ & $10.1 \pm 1.3$ & $5.5 \pm 1.4$ & $7.9 \pm 2.2$ & $2.8 \pm 0.9$ & $2.7 \pm 1.5$ & $4.8 \pm 3.1$ \\
Pre-Alps $(n=10)$ & $11.2 \pm 1.8$ & $7.2 \pm 2.0$ & $9.8 \pm 2.3$ & $3.3 \pm 0.9$ & $3.3 \pm 1.8$ & $4.5 \pm 4.8$ \\
Alps $(n=14)$ & $9.9 \pm 2.3$ & $5.7 \pm 2.1$ & $8.6 \pm 2.6$ & $3.4 \pm 0.8$ & $3.2 \pm 1.3$ & $5.4 \pm 4.7$ \\
Tessin $(n=10)$ & $12.8 \pm 1.2$ & $9.4 \pm 3.4$ & $10.9 \pm 2.2$ & $3.4 \pm 0.9$ & $4.1 \pm 1.0$ & $4.8 \pm 5.5$ \\
& & & & & \\
\hline$I_{\mathrm{m}}(1 \mathrm{~h})$ & All events & No lightning & Lightning & $\beta<0.2$ & $0.2<\beta<0.8$ & $\beta>0.8$ \\
\hline All stations $(n=59)$ & $9.5 \pm 1.9$ & $4.7 \pm 2.5$ & $7.6 \pm 2.7$ & $3.3 \pm 1.2$ & $3.0 \pm 1.3$ & $6.9 \pm 3.3$ \\
Plateau $(n=25)$ & $9.4 \pm 1.3$ & $4.4 \pm 1.7$ & $7.8 \pm 2.1$ & $2.7 \pm 0.8$ & $3.4 \pm 1.3$ & $6.2 \pm 3.0$ \\
Pre-Alps $(n=10)$ & $10.3 \pm 2.1$ & $5.0 \pm 2.9$ & $8.5 \pm 3.2$ & $3.5 \pm 1.0$ & $3.0 \pm 0.6$ & $7.3 \pm 4.1$ \\
Alps $(n=14)$ & $9.3 \pm 2.9$ & $4.1 \pm 3.1$ & $6.2 \pm 3.5$ & $3.9 \pm 1.3$ & $2.4 \pm 1.2$ & $7.7 \pm 3.0$ \\
Tessin $(n=10)$ & $9.4 \pm 1.0$ & $5.9 \pm 2.7$ & $8.1 \pm 1.7$ & $3.9 \pm 1.3$ & $3.1 \pm 1.5$ & $6.8 \pm 3.8$ \\
\hline
\end{tabular}

obtain a rate of $10-11 \%{ }^{\circ} \mathrm{C}^{-1} \%$ at this station by both the QR and TB estimation methods. This difference between nolightning and lightning slopes is evident also when dew-point temperature is used instead of mean daily air temperature (see Fig. 3 in the Supplement).

Analysing all stations shows that this is in fact a systematic result. In accordance with the findings of Haerter and Berg (2009) and Berg et al. (2013b), the scaling rates for all events are systematically higher than those of the individual lightning and no-lightning subsets because of the mixing of stratiform events at low temperatures and convective events at high temperatures. This is true for both mean (Fig. 4) and peak (Fig. 5) event intensity and for both $10 \mathrm{~min}$ and $1 \mathrm{~h}$ resolutions, as demonstrated by the bias in the scatter plots between the slopes obtained for lightning and no-lightning subsets and all events. The bias is most evident for the nolightning subset, where the rates are substantially lower than those for all events. Importantly, while the convective lightning subset shows slopes for peak intensity from $10 \mathrm{~min}$ data generally constrained in the $\mathrm{CC}-2 \mathrm{CC}$ range for individual stations, mixing events results in several stations having slopes in excess of the $2 \mathrm{CC}$ rate. There are practically no sta- 

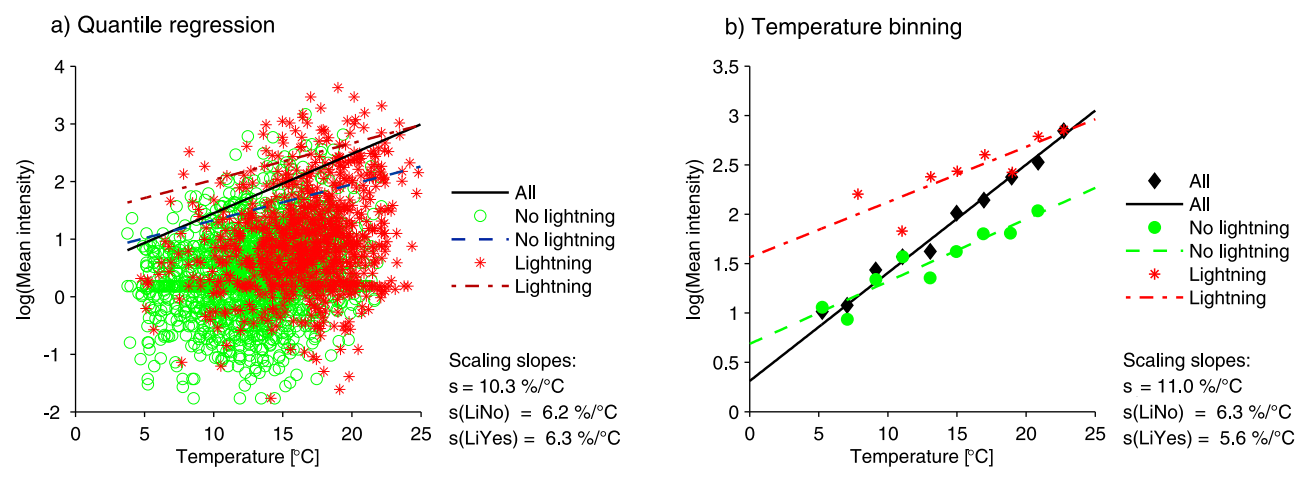

Figure 3. Example of the estimates of scaling slopes by (a) the quantile regression method and (b) the temperature binning method for the Wynau station. Slopes for no-lightning (green, s(LiNo)) and lightning (red, s(LiYes)) events as well as all events together (s) are shown and their magnitudes in $\%{ }^{\circ} \mathrm{C}^{-1}$ are reported. This figure is reproduced for dew-point temperature in the Supplement.

tions that exhibit rates greater than $2 \mathrm{CC}$ in each individual storm type subset, despite the variability between stations.

The box plots for all events and the different event subsets are summarised in Fig. 6 for $I_{\mathrm{m}}$ and $I_{\mathrm{p}}$ for the 95th percentile and the station mean and standard deviation are also reported in Tables 1 and 2. The mean slope for $I_{\mathrm{m}}$ for the no-lightning subset at $10 \mathrm{~min}$ resolution is $6.5 \%{ }^{\circ} \mathrm{C}^{-1}$, which is close to the $\mathrm{CC}$ rate, the lightning subset slope is $8.9 \%{ }^{\circ} \mathrm{C}^{-1}$, which is greater than the $\mathrm{CC}$ rate, while for all events the resulting slope is $10.7 \%{ }^{\circ} \mathrm{C}^{-1}$. For peak event intensity the rates are slightly higher, but the same amplification effect of mixing event types applies. The convective lightning subset slope for $10 \mathrm{~min} I_{\mathrm{p}}$ is $9.3 \%{ }^{\circ} \mathrm{C}^{-1}$ and for all events is $13.0 \%{ }^{\circ} \mathrm{C}^{-1}$.

Analysing the different event subsets based on the convectivity index $\beta$ shows that the highest convectivity range $(\beta>0.8)$ approaches the station average of the lightning subset, especially for the $1 \mathrm{~h}$ data, but with much higher variability in scaling slopes between stations. This suggests that the index may be used as a first approximation to identify convective events when long-term lightning data are not available, provided a reliable estimate of $I^{*}$ can be found.

In summary, the rates for convective events in our data set are mostly in the $\mathrm{CC}-2 \mathrm{CC}$ range for $10 \mathrm{~min}$ data for both mean and peak event intensities, and slightly lower if a coarser $1 \mathrm{~h}$ resolution was used (Fig. 6). The rates are in agreement with the steady-state entraining plume model of Loriaux et al. (2013), who showed that the scaling rate in convective systems can be about $10 \%{ }^{\circ} \mathrm{C}^{-1}$, composed of $7 \%{ }^{\circ} \mathrm{C}^{-1}$ due to thermodynamic effects and $3 \%{ }^{\circ} \mathrm{C}^{-1}$ related to dynamic effects (vertical updraft velocity). Considering additional effects of varying vertical velocity and lateral moisture flux can lead to scaling rates between CC and 2CC for convective storms (Loriaux et al., 2013), which is supported by our data.

The results using both slope estimation methods for the 50th, 90th, 95th, and 99th percentiles show that overall the QR and TB methods provide very similar slope estimates, with a higher variability between stations in the TB method
(Fig. 7). Most notably, differences between the QR and TB methods are smaller than the differences between the lightning and no-lightning subsets. The sensitivity of the results to the $10 \mathrm{~min}$ data is reflected in higher overall slopes than for $1 \mathrm{~h}$ data due to the higher accuracy in determining storm duration and high peak $10 \mathrm{~min}$ intensities (see also Haerter et al., 2010). However, this effect too is smaller than the difference between lightning and no-lightning subsets. Even for the highest analysed quantile (99th percentile) it is clear that the convective set of events provides slopes in the $\mathrm{CC}-2 \mathrm{CC}$ range, and that we do not observe widespread $2 \mathrm{CC}$ rates.

\subsection{Regional variability}

The results indicate a large variability in precipitationtemperature relations across Switzerland. The scaling slopes for the 95th percentile of $I_{\mathrm{m}}$ for lightning and no-lightning events are shown in Fig. 8 and summarised in Tables 1 and 2 for the four studied regions. Overall, the lowest rates in $I_{\mathrm{m}}$ and $I_{\mathrm{p}}$ are found in the Plateau and Alpine stations, while the highest rates are on average in the pre-Alps and in Tessin south of the main Alpine divide. This suggests a regional effect on precipitation intensity influenced not only by temperature but also by general circulation patterns, advection of moisture conditioned by topography, and local surfaceatmosphere feedbacks (see also Ban et al., 2014).

Some of the lowest rates of precipitation increase with air temperature are observed in the main Alpine valleys (e.g. Rhône Valley), where probably both lower temperatures and common temperature inversions combine with complex orographically driven patterns of moisture flow, condensation, and rainfall formation (e.g. Panziera and Germann, 2010). Similarly, high rates in the pre-Alps may be conditioned by moisture convergence and windward ascent, leading to enhanced orographic effects on precipitation in this area (e.g. Siler and Roe, 2014). Outliers are also evident, like the Cimetta (CIM) station in Tessin with very high scaling rates for non-lightning events. This is a very exposed station 
Mean event intensity

a) No Lightning (10-min)

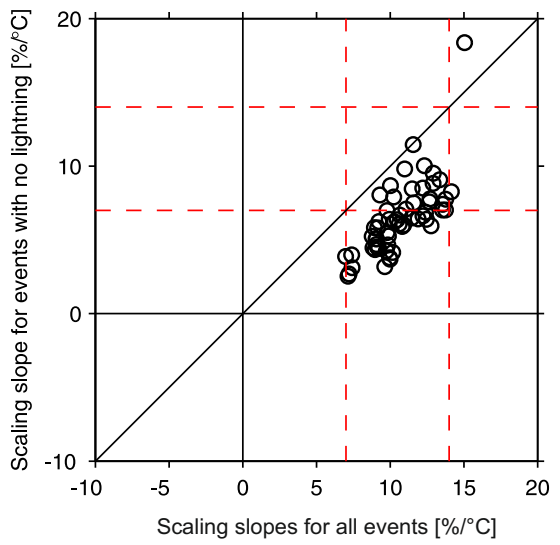

c) No Lightning (1-hr)

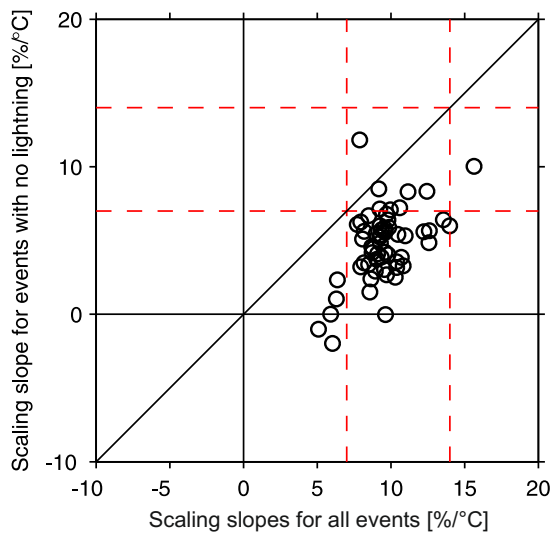

b) Lightning (10-min)

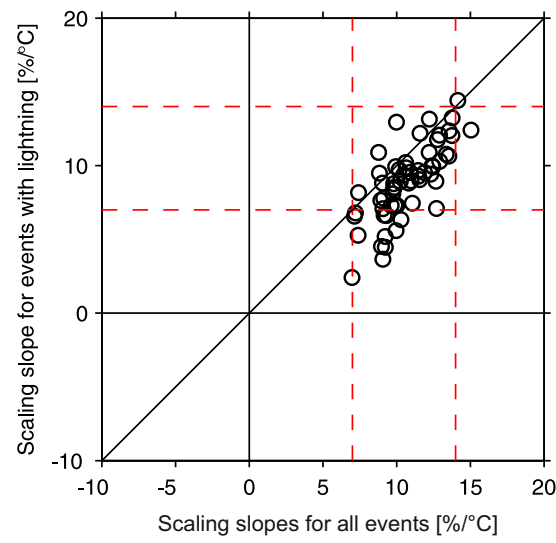

d) Lightning (1-hr)

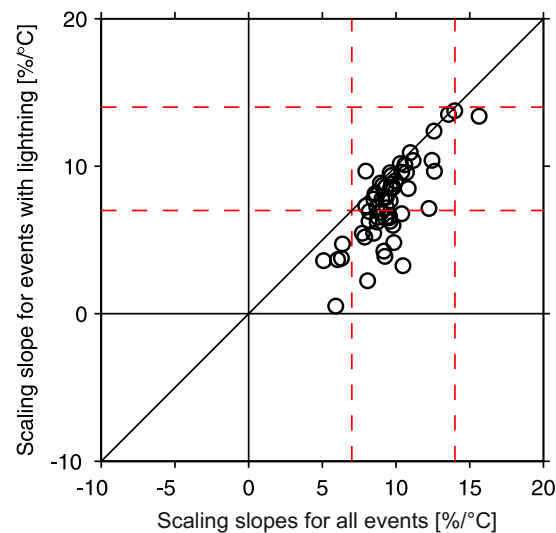

Figure 4. Scatter plots of station-derived estimates of scaling slopes for mean event intensity $I_{\mathrm{m}}$ in lightning and no-lightning events versus all events at the (a-b) $10 \mathrm{~min}$ and (c-d) $1 \mathrm{~h}$ resolutions using the quantile regression method (95th percentile). Red dashed lines indicate the $\mathrm{CC}$ rate $\left(7 \%{ }^{\circ} \mathrm{C}^{-1}\right)$ and $2 \mathrm{CC}$ rate $\left(14 \%{ }^{\circ} \mathrm{C}^{-1}\right)$. The same figure for the temperature binning method is in the Supplement.

Table 2. Means of the regression slopes in $\%{ }^{\circ} \mathrm{C}^{-1}$ fitted to the 95 th percentile by quantile regression \pm 1 standard deviation. Slopes are reported for peak $I_{\mathrm{p}}$ event intensity for $10 \mathrm{~min}$ and $1 \mathrm{~h}$ time resolutions for all events, no-lightning events, lightning events, and storms grouped by the convectivity index $\beta$.

\begin{tabular}{lcccccc}
\hline$I_{\mathrm{p}}(10 \mathrm{~min})$ & All events & No lightning & Lightning & $\beta<0.2$ & $0.2<\beta<0.8$ & $\beta>0.8$ \\
\hline All stations $(n=59)$ & $13.0 \pm 2.0$ & $6.9 \pm 2.7$ & $9.3 \pm 2.6$ & $0.1 \pm 1.0$ & $6.4 \pm 2.2$ & $6.2 \pm 5.3$ \\
Plateau $(n=25)$ & $12.6 \pm 1.0$ & $7.1 \pm 1.5$ & $8.4 \pm 1.4$ & $0.6 \pm 0.6$ & $6.0 \pm 1.6$ & $5.8 \pm 3.6$ \\
Pre-Alps $(n=10)$ & $13.7 \pm 2.6$ & $7.6 \pm 2.1$ & $11.0 \pm 2.6$ & $0.5 \pm 1.1$ & $6.6 \pm 1.9$ & $7.6 \pm 6.2$ \\
Alps $(n=14)$ & $12.0 \pm 2.6$ & $4.4 \pm 3.3$ & $9.2 \pm 3.5$ & $0.1 \pm 0.3$ & $6.6 \pm 1.9$ & $7.6 \pm 6.2$ \\
Tessin $(n=10)$ & $14.4 \pm 1.4$ & $9.0 \pm 2.3$ & $10.0 \pm 2.7$ & $-1.4 \pm 0.8$ & $5.6 \pm 3.2$ & $4.8 \pm 6.8$ \\
\hline$I_{\mathrm{p}}(1 \mathrm{~h})$ & All events & No lightning & Lightning & $\beta<0.2$ & $0.2<\beta<0.8$ & $\beta>0.8$ \\
\hline All stations $(n=59)$ & $8.9 \pm 1.8$ & $3.9 \pm 2.3$ & $5.9 \pm 2.5$ & $0.1 \pm 0.6$ & $3.8 \pm 2.1$ & $6.1 \pm 3.7$ \\
Plateau $(n=25)$ & $9.1 \pm 0.9$ & $4.6 \pm 1.5$ & $6.7 \pm 1.3$ & $0.1 \pm 0.4$ & $4.7 \pm 1.6$ & $5.8 \pm 4.0$ \\
Pre-Alps $(n=10)$ & $9.5 \pm 1.9$ & $5.3 \pm 2.1$ & $7.0 \pm 3.1$ & $0.4 \pm 0.6$ & $4.7 \pm 2.4$ & $8.0 \pm 3.1$ \\
Alps $(n=14)$ & $8.2 \pm 3.1$ & $2.2 \pm 2.8$ & $3.7 \pm 3.0$ & $0.5 \pm 0.5$ & $1.8 \pm 1.8$ & $5.8 \pm 2.9$ \\
Tessin $(n=10)$ & $8.7 \pm 1.2$ & $3.1 \pm 1.5$ & $5.8 \pm 1.5$ & $-0.7 \pm 0.6$ & $3.7 \pm 1.5$ & $5.4 \pm 4.2$ \\
\hline
\end{tabular}


Peak event intensity

a) No Lightning (10-min)

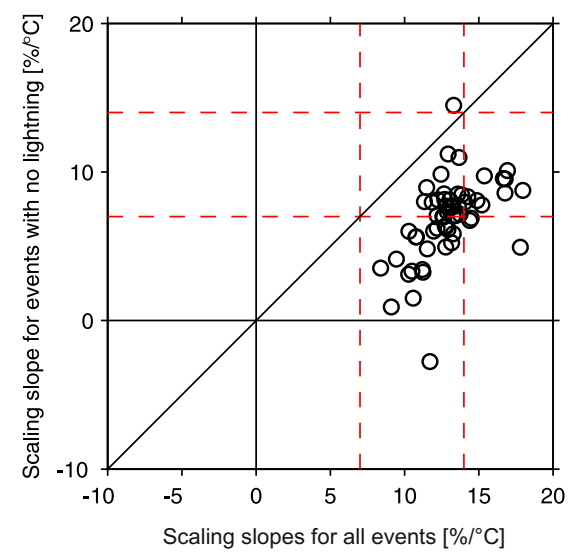

c) No Lightning (1-hr)

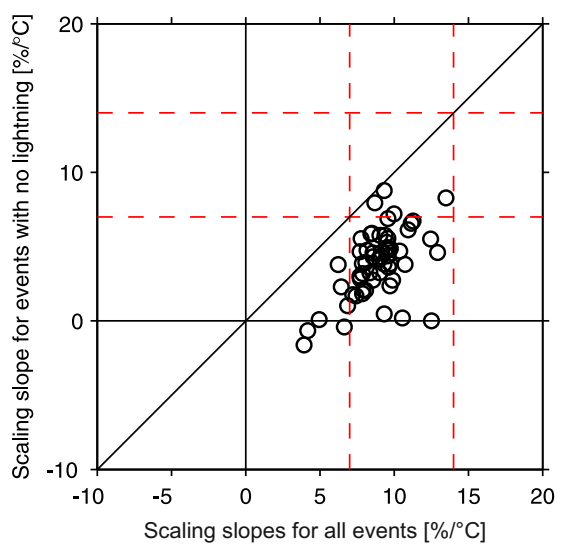

b) Lightning (10-min)

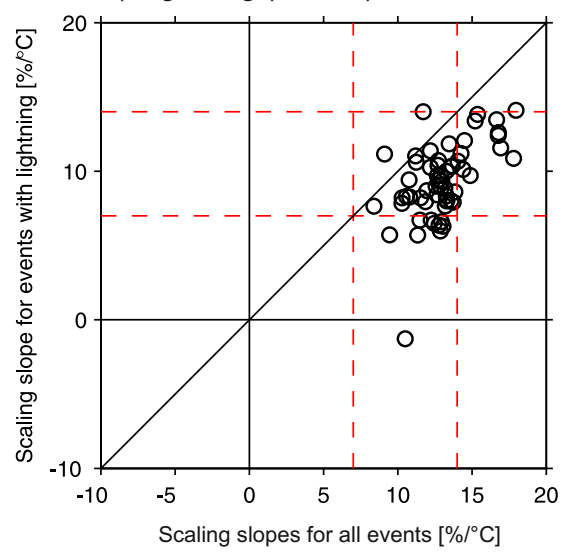

d) Lightning (1-hr)

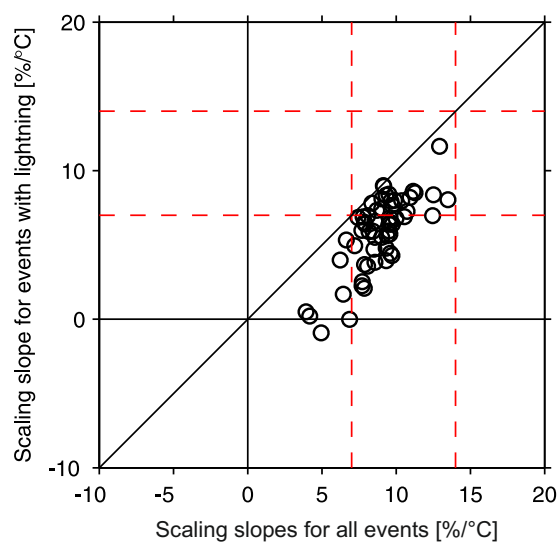

Figure 5. Scatter plots of station-derived estimates of scaling slopes for peak event intensity $I_{\mathrm{p}}$ in lightning and no-lightning events versus all events at the (a-b) $10 \mathrm{~min}$ and (c-d) $1 \mathrm{~h}$ resolutions using the quantile regression method (95th percentile). Red dashed lines indicate the $\mathrm{CC}$ rate $\left(7 \%{ }^{\circ} \mathrm{C}^{-1}\right)$ and $2 \mathrm{CC}$ rate $\left(14 \%{ }^{\circ} \mathrm{C}^{-1}\right)$. The same figure for the temperature binning method is in the Supplement.

on a mountain hillslope where we have concerns about the quality and representativeness of the lightning observations.

The issue of moisture availability has been raised as a possible limitation on the rates of precipitation increase at high temperatures (e.g. Hardwick Jones et al., 2010; Lenderink and Van Meijgaard, 2010; Lenderink et al., 2011; Panthou et al., 2014; Westra et al., 2014). The relation of mean daily relative humidity to air temperature for nine stations in our data set representative of the different regions shows that there are indeed possible limitations of moisture availability at higher temperatures when relative humidity on rainy days drops and follows an almost constant vapour pressure curve (Fig. 9). Stations in mountain valleys (e.g. Davos, Zermatt) are typically moisture limited at a lower temperature, which suggests that there could be an orographic shielding of inner Alpine valleys, with the moisture content of the warmer air being depleted before arriving in these valleys. Similar moisture limitations have been described on a larger continental scale in the US and Canada (Mishra et al., 2012; Panthou et al., 2014). As an alternative to using precipitation-dewpoint temperature relations to identify moisture limitations, it is possible to define moisture-limiting threshold temperatures from data such as presented in Fig. 9 for different daily rainfall sums and/or event totals.

\subsection{Evidence of change in convective events}

The presented positive relations of precipitation intensity to temperature across Switzerland suggest that precipitation should exhibit some signal of change in a warming climate. Previous studies have found that precipitation (especially winter precipitation) and air temperature have increased in the last century in the wider European Alpine region and in Switzerland (e.g. Beniston et al., 1994; Widmann and Schaer, 1997; Brunetti et al., 2009). However, changes in extreme rainfall in Switzerland from daily precipitation records have 

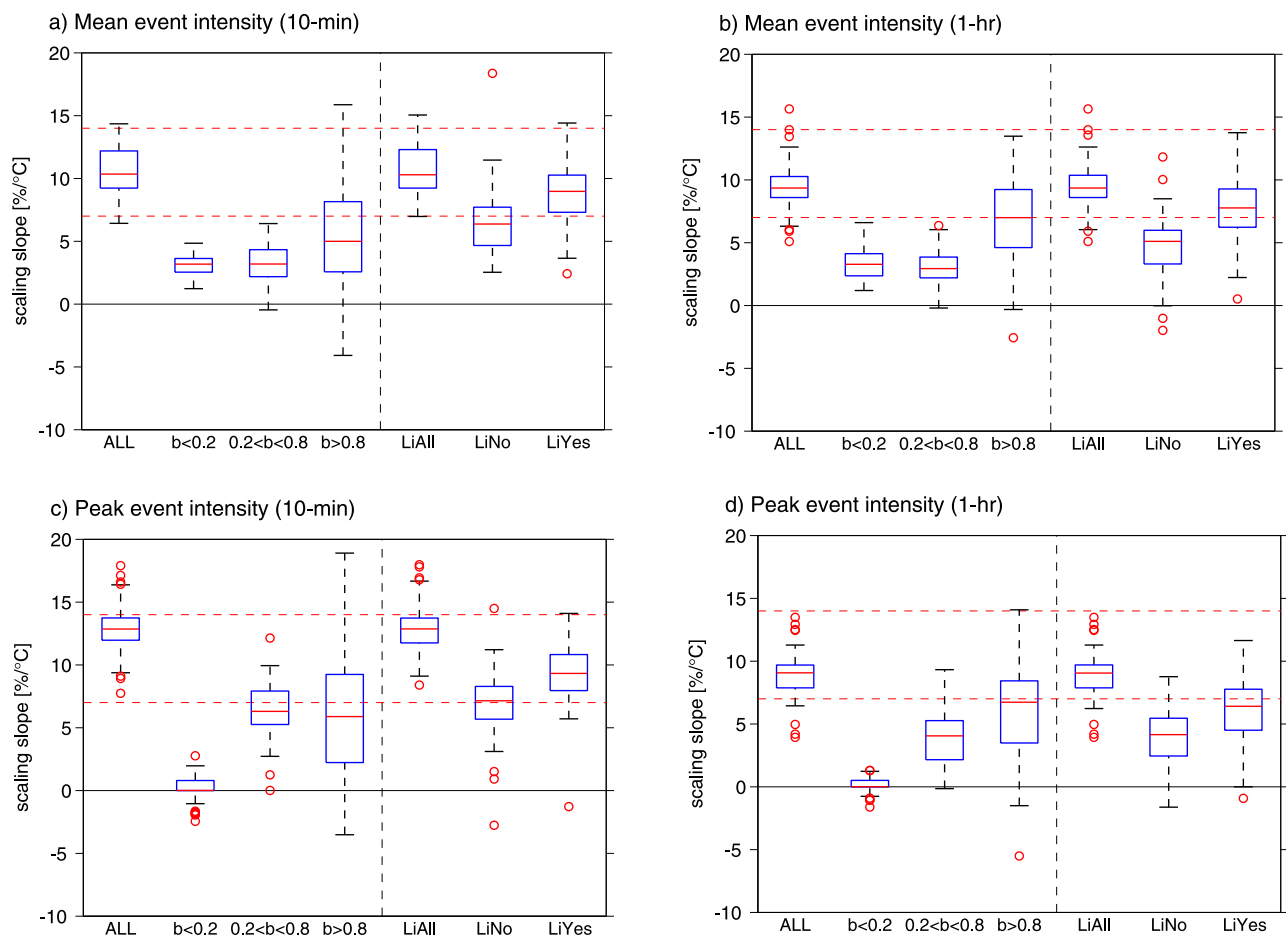

Figure 6. Box plots showing the distributions of scaling slope magnitude for mean event intensity $I_{\mathrm{m}}$ at the (a) $10 \mathrm{~min}$ scale and (b) $1 \mathrm{~h}$ scale, and for peak event intensity $I_{\mathrm{p}}$ at the (c) $10 \mathrm{~min}$ scale and (d) $1 \mathrm{~h}$ scale. The slopes were estimated using the quantile regression method for the 95th percentile. The data are organised into different subgroups (from left) using all events (1981-2011, ALL), three convectivity levels, all events with lightning data (1987-2011, LiAll), and the division into no-lightning (LiNo) and lightning (LiYes) subsets. The red line shows the median; the upper and lower bounds are the 25 th and 75 th percentiles $(25 \mathrm{P}$ and $75 \mathrm{P})$. The whiskers are calculated as $75 \mathrm{P} \pm 1.5(75 \mathrm{P}-25 \mathrm{P})$. Outliers are plotted as red circles. The horizontal dashed line shows the $\mathrm{CC}$ rate $\left(7 \%{ }^{\circ} \mathrm{C}^{-1}\right)$ and $2 \mathrm{CC}$ rate $\left(14 \%{ }^{\circ} \mathrm{C}^{-1}\right)$. The same figure for the temperature binning method is in the Supplement.

been rather small and spatially inconsistent (e.g. Frei and Schaer, 2001; Birsan et al., 2005). In the context of this paper, it is interesting to know whether changes in the frequency and intensity of convective events can be demonstrated from data, since these produce the highest rainfall intensities. The proportion of convective events, i.e. those accompanied by lightning, in our data set is strongly dependent on air temperature and varies from $30 \%$ at low temperatures to more than $80 \%$ at temperatures above $25^{\circ} \mathrm{C}$ (Fig. 10).

The change in the frequency of estimated convective events in our study, defined by the number of events per year during which the peak $10 \mathrm{~min}$ intensity exceeded the threshold $I^{*}$, shows that $90 \%$ of the stations exhibited upward trends and $30 \%$ were statistically significant in the period 1981-2011 (Fig. 11). Statistically significant trends (MannKendall test) were distributed across the country, suggesting that more intense (convective) storms in this part of Europe in the April-September period over the last 30 years may have taken place. This increasing tendency may be connected with a general warming and rise in convective available potential energy and more lightning (e.g. Romps et al., 2014), but may also be part of natural variability or trends connected with large-scale atmospheric circulation patterns (see also Fatichi et al., 2015). Searching for possible changes in atmospheric circulation and the occurrence of intense convective rain in the Alpine area remains an important open research question.

\section{Conclusions}

This study complements previous data-based investigations of precipitation increases with air temperature with an analysis of 30 years of $10 \mathrm{~min}$ and $1 \mathrm{~h}$ records from 59 stations in an area with high relief and complex topography. Scaling of extreme rainfall on an event basis is analysed to find evidence of super-CC scaling rates. The novelty in our work is that we used storm event properties, rather than fixed time intervals, and we separated events into stratiform and convective sets based on lightning. Our main conclusions are the following.

1. Station mean event intensity $I_{\mathrm{m}}$ and peak $10 \mathrm{~min}$ intensity $I_{\mathrm{p}}$ of extreme rainstorms increased with air temperature at super-CC rates. However, these rates are amplified by the mixing of storm types as already discussed by Berg et al. (2013b). Events accompanied by lightning (convective events) exhibit consistently higher rates of increase with air temperature than stratiform events, but 

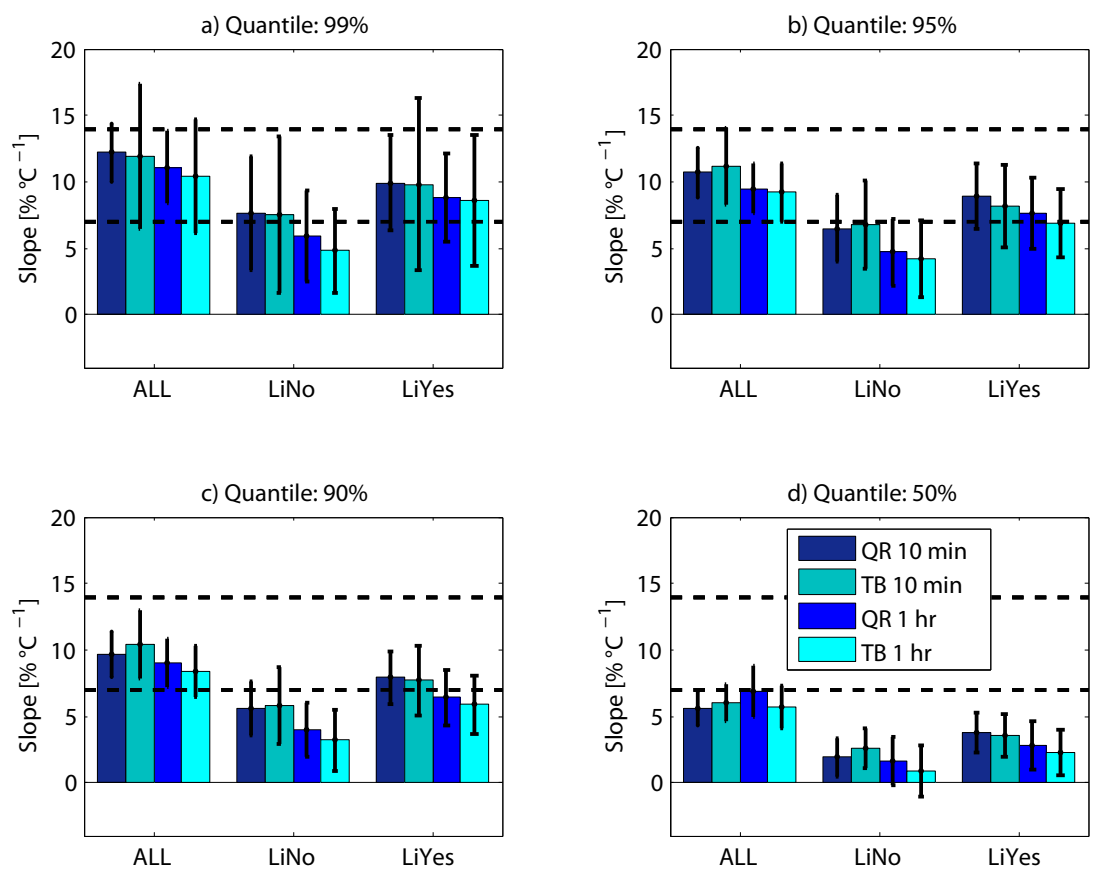

Figure 7. The mean and \pm 1 standard deviation of the scaling slope estimates for mean event intensity $I_{\mathrm{m}}$ for all events (ALL) consisting of lightning (LiYes) and no-lightning (LiNo) subsets for the quantile regression method (QR) and the temperature binning method (TB) and both studied resolutions $10 \mathrm{~min}$ and $1 \mathrm{~h}$. Results are reported for the (a) 99th, (b) 95th, (c) 90th, and (d) 50th percentiles.
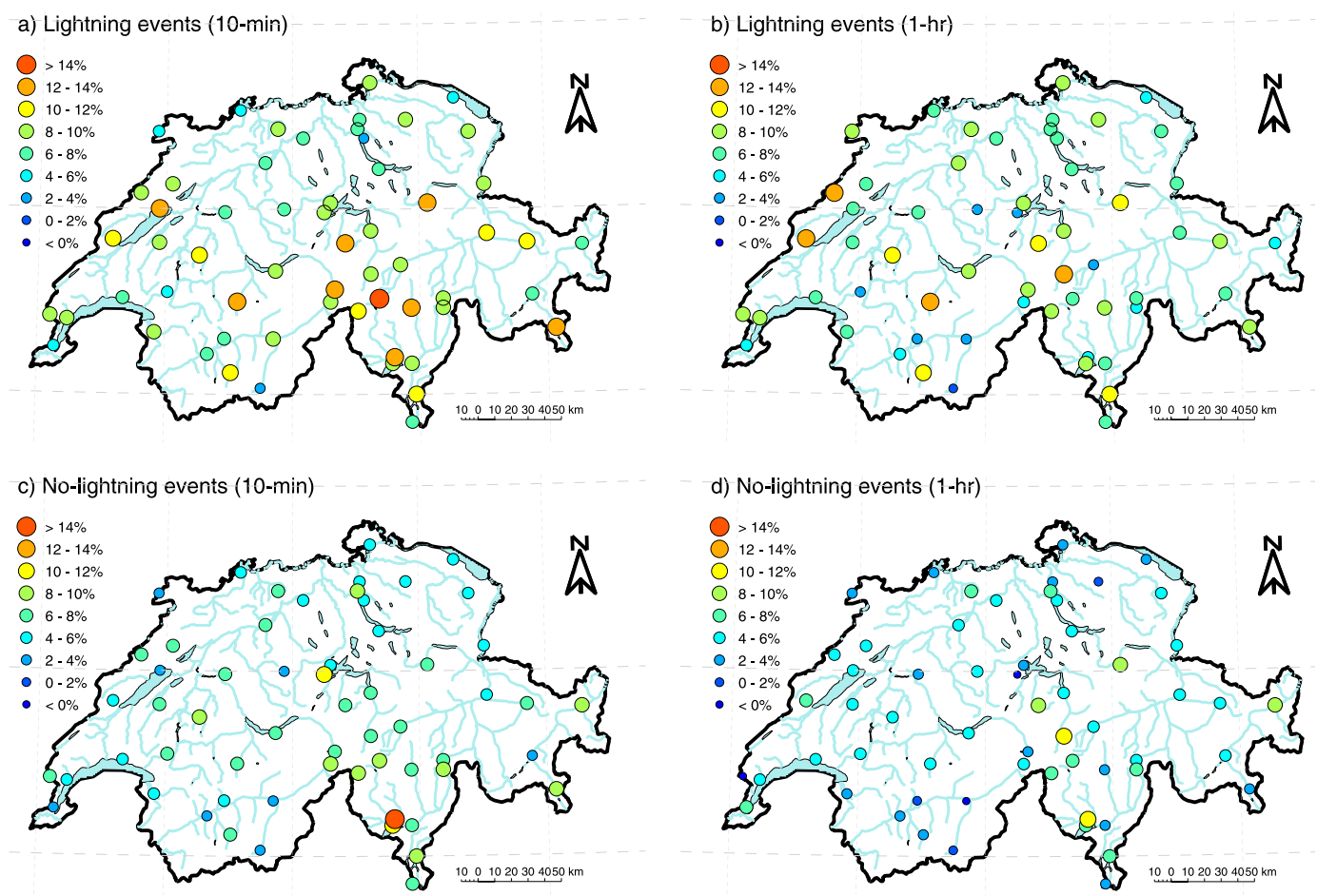

Figure 8. Spatial maps of scaling slopes for mean event intensity $I_{\mathrm{m}}$ for lightning events at the (a) $10 \mathrm{~min}$ and (b) $1 \mathrm{~h}$ resolutions, and no-lightning events at the (c) $10 \mathrm{~min}$ and (d) $1 \mathrm{~h}$ resolutions for the 95th percentile estimated with the quantile regression method. The colour and size of the legend markers indicate the scaling slope magnitude in $\%{ }^{\circ} \mathrm{C}^{-1}$. The same figure for the temperature binning method is in the Supplement. 

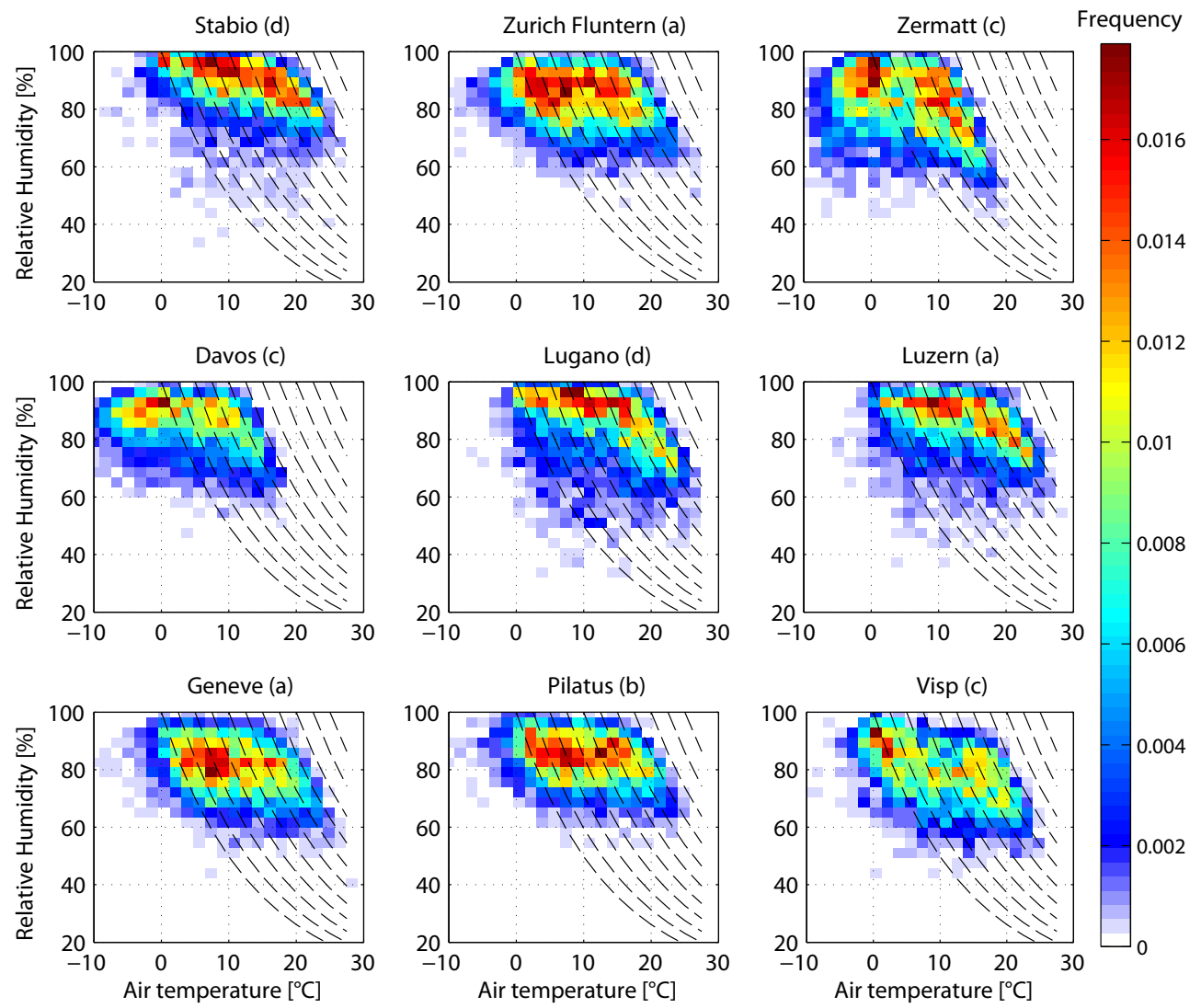

Figure 9. Relative frequency of mean daily relative humidity as a function of mean daily air temperature for wet days (precipitation higher than $1 \mathrm{~mm} \mathrm{day}^{-1}$ ) at nine representative stations in the four regions in our data set: (a) Plateau, (b) pre-Alps, (c) Alps, (d) Tessin. Constant vapour pressure curves are shown with dashed lines.

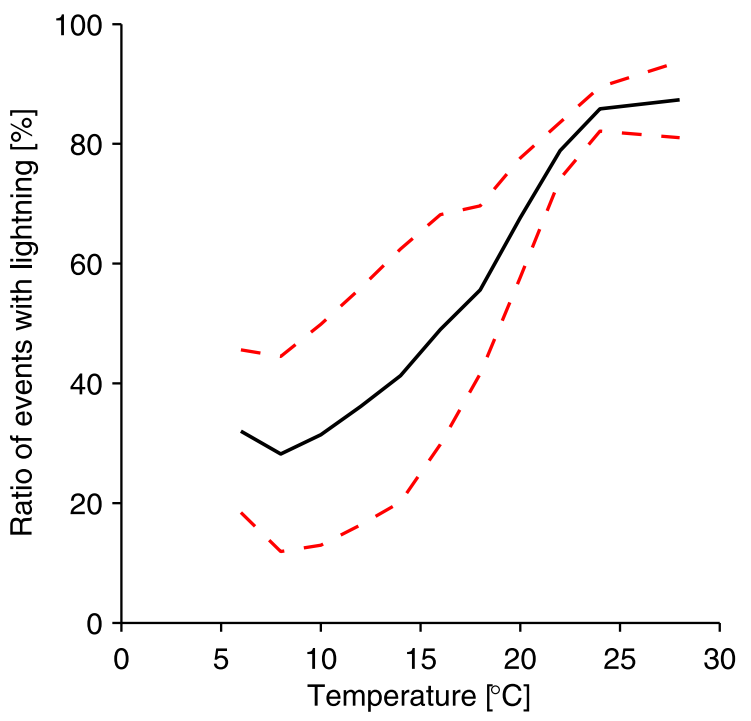

Figure 10. The average percentage of lightning events in the set of all events as a function of air temperature for the 59 studied stations. Red lines give bounds \pm 1 standard deviation. both storm types have lower rates than when all of the events are combined. Rates exceeding $2 \mathrm{CC}$ observed in some previous studies are an exception in our data set, even for the 99th percentiles in convective storms.

2. The large spatial variability in precipitationtemperature relations across Switzerland, especially the low scaling rates in deep Alpine valleys and high rates in the pre-Alps, suggests that precipitation-temperature relations are influenced not only by temperature, but also by general circulation patterns and local advection of moisture conditioned by topography. We demonstrate on some representative stations that there are possible limitations of moisture availability at high temperatures.

3. The number of convective events, identified as those in which the peak 10 min intensity exceeded a threshold $I^{*}$ calibrated with lightning data has increased across Switzerland in the past 30 years. We found that the majority of the stations exhibited upward trends in the period 1981-2011 and that 30\% were statistically significant. The changes in intense (convective) storms at higher temperatures may as a consequence lead to 


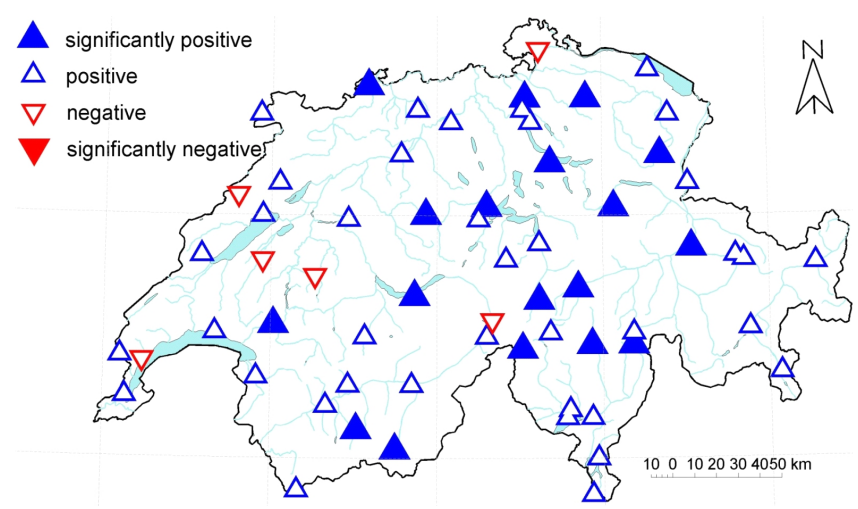

Figure 11. Trends in the number of events per year in which $I_{\mathrm{p}}>I^{*}$ over the period 1981-2011 estimated by the non-parametric MannKendall trend test. Upward trends are blue, downward trends are red, and statistically significant trends at the $\alpha=10 \%$ significance level have filled markers.

higher hydrological risk connected with short-duration extreme rainfall.

Overall, our main finding is that $2 \mathrm{CC}$ rates of increase in rainfall with temperature reported by others (e.g. Lenderink and Van Meijgaard, 2008, 2010; Allan and Soden, 2008; Lenderink et al., 2011; Loriaux et al., 2013) are rare and rather an exception in our data set, even for convective rainfall. Mixing of storm types has an important impact on the scaling rates. While increases in convective (lightning) events are between 8 and $9 \%{ }^{\circ} \mathrm{C}^{-1}$ and in stratiform (nolightning) events between 6 and $7 \%{ }^{\circ} \mathrm{C}^{-1}$ for mean and peak 10 min intensity, the mixing of events resulted in scaling rates between 11 and $13 \%{ }^{\circ} \mathrm{C}^{-1}$ on average. Which scaling rates apply to extreme precipitation in a warmer future depends on the air temperature at which these events will occur and on the relative proportion of storm types at that temperature.

We also observe large variability in the scaling rates between stations, which are likely connected with atmospheric moisture supply dynamics combined with topographic effects. Uncertainties in the estimate of the slopes from data and the inherent stochasticity of the rainfall process can be additional causes of variability. However, we think that the storm type effects and heterogenous patterns in extreme rainfall intensity-temperature relations are robust results indicative of the complex topography and atmospheric moisture supply patterns in Switzerland and possibly other regions.

\section{The Supplement related to this article is available online at doi:10.5194/hess-19-1753-2015-supplement.}

Acknowledgements. This research was conducted by a series of investigations with ETH Zurich MSc students, in particular C. Berger and I. Ismail, and collaboration between ETH Zurich and SUT Bratislava over the period 2012-2014. It was presented at the International Precipitation Conference (IPC11) in Wageningen in 2013. Funding was provided by the Swiss National Science Foundation to P. Molnar (grant 20021-120310), the Sciex-NMS Scientific Exchange Programme (grant 11.034) and the Marie Curie Intra European Fellowship (grant 301953 IMPALA) to L. Gaál. L. Gaál and J. Szolgay also acknowledge the support of the Slovak Research and Development Agency (grant APVV-0303-11) and the VEGA Agency (grant 1/0776/13). MeteoSwiss provided the hydroclimatic data.

Edited by: H. Leijnse

\section{References}

Allan, R. P. and Soden, B. J.: Atmospheric warming and the amplification of precipitation extremes, Science, 321, 1481-1484, doi:10.1126/science.1160787, 2008.

Allan, R. P., Liu, C., Zahzn, M., Lavers, D. A., Koukouvagias, E., and Bodas-Salcedo, A.: Physically consistent responses of the global atmospheric hydrological cycle in models and observations, Surv. Geophys., 35, 533-552, doi:10.1007/s10712-0129213-z, 2014.

Ban, N., Schmidli, J., and Schär, C.: Evaluation of the convection-resolving regional climate modeling approach in decade-long simulations, J. Geohys. Res., 119, 7889-7907, doi:10.1002/2014JD021478, 2014.

Beniston, M., Rebetez, M., Giorgi, F., and Marinucci, M. R.: An analysis of regional climate-change in Switzerland, Theor. Appl. Climatol., 49, 135-159, doi:10.1007/BF00865530, 1994.

Berg, P. and Haerter, J. O.: Unexpected increase in precipitation intensity with temperature - A result of mixing of precipitation types? Atmos. Res., 119, 56-61, doi:10.1016/j.atmosres.2011.05.012, 2013a.

Berg, P., Haerter, J. O., Thejll, P., Piani, C., Hagemann, S., and Christensen, J. H.: Seasonal characteristics of the relationship between daily precipitation intensity and surface temperature, J. Geophys. Res., 114, D18102, doi:10.1029/2009JD012008, 2009.

Berg, P., Moseley, C., and Haerter, J. O.: Strong increase in convective precipitation in response to higher temperatures, Nat. Geosci., 6, 181-185, doi:10.1038/NGEO1731, 2013b.

Birsan, M. V., Molnar, P., Pfaundler, M., and Burlando, P.: Streamflow trends in Switzerland, J. Hydrol., 314, 312-329, doi:10.1016/j.jhydrol.2005.06.008, 2005.

Brunetti, M., Lentini, G., Maugeri, M., Nanni, T., Auer, I., Boehm, R., and Schoener, W.: Climate variability and change in the Greater Alpine Region over the last two centuries based on multivariable analysis, Int. J. Climatol., 29, 2197-2225, doi:10.1002/joc.1857, 2009.

Chvila, B., Sevruk, B., and Ondras, M.: The wind-induced loss of thunderstorm precipitation measurements, Atmos. Res., 77, 29_ 38, doi:10.1016/j.atmosres.2004.11.032, 2005.

Dunkerley, D. L.: How do the rain rates of sub-event intervals such as the maximum 5- and $15-\mathrm{min}$ rates $\left(I_{5}\right.$ or $\left.I_{30}\right)$ relate to the 
properties of the enclosing rainfall event?, Hydrol. Process., 24, 2425-2439, doi:10.1002/hyp.7650, 2010.

Fatichi, S., Barbosa, S. M., Caporali, E., and Silva, M. E.: Deterministic versus stochastic trends: Detection and challenges, J. Geophys. Res., 114, D18121, doi:10.1029/2009JD011960, 2009.

Fatichi, S., Molnar, P., Mastrotheodoros, T., and Burlando, P.: Diurnal and seasonal changes in near surface humidity in a complex orography, J. Geophys. Res.-Atmos., 120, doi:10.1002/2014JD022537, in press, 2015.

Frei, C. and Schaer, C.: Detection probability of trends in rare events: Theory and application to heavy precipitation in the Alpine region, J. Climate, 14, 1568-1584, doi:10.1175/15200442(2001)014<1568:DPOTIR>2.0.CO;2, 2001.

Gaál, L., Molnar, P., and Szolgay, J.: Selection of intense rainfall events based on intensity thresholds and lightning data in Switzerland, Hydrol. Earth Syst. Sci, 18, 1561-1573, doi:10.5194/hess-18-1561-2014, 2014.

Grace, R. A. and Eagleson, P. S.: A model for generating synthetic sequences of short-time-interval rainfall depths, in: Proceedings of International Hydrology Symposium, Fort Collins, Colorado, 268-276, 1967.

Grungle, B. and Krider, P.: Cloud-to-ground lightning and surface rainfall in warm-season Florida thunderstorms, J. Geophys. Res., 111, D19203, doi:10.1029/2005JD006802, 2006.

Haerter, J. O. and Berg, P.: Unexpected rise in extreme precipitation caused by a shift in rain type?, Nat. Geosci., 2, 372-373, doi:10.1038/ngeo523, 2009.

Haerter, J. O., Berg, P., and Hagemann, S.: Heavy rain intensity distributions on varying time scales and at different temperatures, J. Geophys. Res., 115, D17102, doi:10.1029/2009JD013384, 2010.

Hardwick Jones, R., Westra, S., and Sharma, A.: Observed relationships between extreme sub-daily precipitation, surface temperature, and relative humidity, Geophys. Res. Lett., 37, L22805, doi:10.1029/2010GL045081, 2010.

Lang, S., Tao, W. K., Simpson, J., and Ferrier, B.: Modeling of convective-stratiform precipitation processes: Sensitivity to partitioning methods, J. Appl. Meteor., 42, 505-527, doi:10.1175/1520-0450(2003)042<0505:MOCSPP>2.0.CO;2, 2003.

Lenderink, G. and Van Meijgaard, E.: Increase in hourly precipitation extremes beyond expectations from temperature changes, Nat. Geosci., 1, 511-514, doi:doi:10.1038/ngeo262, 2008.

Lenderink, G. and Van Meijgaard, E.: Linking increases in hourly precipitation extremes to atmospheric temperature and moisture changes, Environ. Res. Lett., 5, 025208, doi:10.1088/17489326/5/2/025208, 2010.

Lenderink, G., Mok, H. Y., Lee, T. C., and van Oldenborgh, G. J.: Scaling and trends of hourly precipitation extremes in two different climate zones - Hong Kong and the Netherlands, Hydrol. Earth Syst. Sci., 15, 3033-3014, doi:10.5194/hess-15-30332011, 2011.

Llasat, M. C.: An objective classification of rainfall events on the basis of their convective features: application to rainfall intensity in the Northeast of Spain, Int. J. Climatol., 21, 1385-1400, doi:10.1002/joc.692, 2001.

Llasat, M. C., Rigo, T., Ceperuelo, M., and Barrera, A.: Estimation of convective precipitation: the meteorological radar versus an automatic rain gauge network, Adv. Geosci., 2, 103-109, doi:10.5194/adgeo-2-103-2005, 2005.
Llasat, M. C., Ceperuelo, M., and Rigo, T.: Rainfall regionalization on the basis of the precipitation convective features using a raingauge network and weather radar observations, Atmos. Res., 83, 415-426, doi:10.1016/j.atmosres.2005.08.014, 2007.

Loriaux, J. M., Lenderink, G., De Roode, S. R., and Pier Siebsma, A.: Understanding convective extreme precipitation scaling using observations and an entraining plume model, J. Atmos. Sci., 70, 3641-3655, doi:10.1175/JAS-D-12-0317.1, 2013.

Mishra, V., Wallace, J. M., and Lettenmaier, D. P.: Relationship between hourly extreme precipitation and local air temperature in the United States, Geophys. Res. Lett., 39, L16403, doi:10.1029/2012GL052790, 2012.

Molnar, P. and Burlando, P.: Variability in the scale properties of high-resolution precipitation data in the Alpine climate of Switzerland, Water Resour. Res., 44, W10404, doi:10.1029/2007WR006142, 2008.

Mosley, C., Berg, P., and Haerter, J. O.: Probing the precipitation life cycle by iterative rain cell tracking, 118, 13361-13370, doi:10.1002/2013JD020868, 2013.

O'Gorman, P. A.: Sensitivity of tropical precipitation extremes to climate change, Nat. Geosci., 5, 697-700, doi:10.1038/NGEO1568, 2012.

O'Gorman, P. A. and Schneider, T.: The physical basis for increases in precipitation extremes in simulations of 21stcentury climate, P. Natl. Acad. Sci. USA, 106, 14773-14777, doi:10.1073/pnas.0907610106, 2009a.

O'Gorman, P. A. and Schneider, T.: Scaling of precipitation extremes over a wide range of climates simulated with an idealized GCM, J. Climate, 22, 5676-5685, doi:10.1175/2009JCLI2701.1, 2009b.

Pall, P., Allen, M. R., and Stone, D. A.: Testing the Clausius-Clapeyron constraint on changes in extreme precipitation under $\mathrm{CO}_{2}$ warming, Clim. Dynam., 28, 351-363, doi:10.1007/s00382-006-0180-2, 2007.

Panthou, G., Mailhot, A., Laurence E., and Talbot, G.: Relationship between surface temperature and extreme rainfalls: A multitime-scale and event-based analysis, J. Hydromet., 15, 19992011, doi:10.1175/JHM-D-14-0020.1, 2014.

Panziera, L. and Germann, U.: The relation between airflow and orographic precipitation on the southern side of the Alps as revealed by weather radar, Q. J. Roy. Meteorol. Soc., 136, 222238, doi:10.1002/qj.544, 2010.

Paschalis, A., Molnar, P., and Burlando, P.: Temporal dependence structure in weights in a multiplicative cascade model for precipitation, Water Resour. Res., 48, W01501, doi:10.1029/2011WR010679, 2012.

Paschalis, A., Molnar, P., Fatichi, S., and Burlando, P.: A stochastic model for high-resolution space-time precipitation simulation, Water Resour. Res., 49, 8400-8417, doi:10.1002/2013WR014437, 2013.

Paschalis, A., Molnar, P., Fatichi, S., and Burlando, P.: On temporal stochastic modeling of precipitation, nesting models across scales, Adv. Water Resour., 63, 152-166, doi:10.1016/j.advwatres.2013.11.006, 2014.

Pešice, P., Sulan, J., and Řezáčová, D.: Convection precursors in the Czech territory, Atmos. Res., 67-69, 523-532, doi:10.1016/S0169-8095(03)00070-X, 2003. 
Petersen, W. A. and Rutledge, S. A.: On the relationship between cloud-to-ground lightning and convective rainfall, J. Geophys. Res., 103, 14025-14040, doi:10.1029/97JD02064, 1998.

Price, C. and Federmesser, B.: Lightning-rainfall relationships in Mediterranean winter thunderstorms, Geophys. Res. Lett., 33, L07813, doi:10.1029/2005GL024794, 2006.

Restrepo-Posada, P. J. and Eagleson, P. S.: Identification of independent rainstorms, J. Hydrol., 55, 303-319, doi:10.1016/00221694(82)90136-6, 1982.

Rigo, T. and Llasat, M. C.: A methodology for the classification of convective structures using meteorological radar: Application to heavy rainfall events on the Mediterranean coast of the Iberian Peninsula, Nat. Hazards Earth Syst. Sci., 4, 59-68, doi:10.5194/nhess-4-59-2004, 2004.

Roderick, M. L., Sun, F., Lim, W. H., and Farquhar, G. D.: A general framework for understanding the response of the water cycle to global warming over land and ocean, Hydrol. Earth Syst. Sci., 18, 1575-1589, doi:10.5194/hess-18-1575-2014, 2014.

Romps, D. M., Seeley, J. T., Vollaro, D., and Molinari, J.: Projected increase in lightning strikes in the United States due to global warming, Science, 346, 851-854, doi:10.1126/science.1259100, 2014.

Rulfová, Z. and Kyselý, J.: Disaggregating convective and stratiform precipitation from station weather data, Atmos. Res., 134, 100-115, doi:10.1016/j.atmosres.2013.07.015, 2013.

Schneider, T., O'Gorman, P. A., and Levine, X. J.: Water vapor and the dynamics of climate changes, Rev. Geophys., 48, RG3001, doi:10.1029/2009RG000302, 2010.

Shaw, S. B., Royem, A. A., and Riha, S. J.: The relationship between extreme hourly precipitation and surface temperature in different hydroclimatic regions of the United States, J. Hydrometeorol., 12, 319-325, doi:10.1175/2011JHM1364.1, 2011.

Siler, N. and Roe, G.: How will orographic precipitation respond to surface warming? An idealized thermodynamic perspective, Geophys. Res. Lett., 41, 2606-2613, doi:10.1002/2013GL059095, 2014.
Tapia, A., Smith, J. A., and Dixon, M.: Estimation of convective rainfall from lighnting observations, J. Appl. Meteorol., 37, 1497-1509, doi:10.1175/15200450(1998)037<1497:EOCRFL>2.0.CO;2, 1998.

Trenberth, K. E.: Conceptual framework for changes of extremes of the hydrological cycle with climate change, Clim. Change, 42, 327-339, doi:10.1023/A:1005488920935, 1999.

Trenberth, K. E., Dai, A., Rasmussen, R. M., and Parsons, D. B.: The changing character of precipitation, B. Am. Meteorol. Soc., 84, 1205-1217, doi:10.1175/BAMS-84-9-120, 2003.

Utsumi, N., Seto, S., Kanae, S., Maeda, E. E., and Oki, T.: Does higher surface temperature intensify extreme precipitation? Geophys. Res. Lett., 38, L16708, doi:10.1029/2011GL048426, 2011.

Wasko, C. and Sharma, A.: Quantile regression for investigating scaling of extreme precipitation with temperature, Water Resour. Res., 50, 3608-3614, doi:10.1002/2013WR015194, 2014.

Westra, S., Fowler, H. J., Evans, J. P., Alexander, L. V., Berg, P., Johnson, F., Kendon, E. J., Lenderink, G., and Roberts, N. M.: Future changes to the intensity and frequency of short-duration extreme rainfall, Rev. Geophys., 52, 522-555, doi:10.1002/2014RG000464, 2014.

Widmann, M. and Schaer, C.: A principal component and longterm trend analysis of daily precipitation in Switzerland, Int. J. Climatol., 17, 1333-1356, doi:10.1002/(SICI)10970088(199710)17:12<1333::AID-JOC108>3.0.CO;2-Q, 1997.

Yair, Y., Lynn, B., Price, C., Kotroni, V., Lagouvardos, K., Morin, E., Mugnai, A., and Llasat, M. C.: Predicting the potential for lightning activity in Mediterranean storms based on the Weather Research and Forecasting (WRF) model dynamic and microphysical fields, J. Geophys. Res., 115, D04205, doi:10.1029/2008JD010868, 2010. 